\title{
State of the Places of Senile Dementia in the Old Hospice of the City of Lubumbashi
}

\author{
Fabrice Lele Mutombo ${ }^{1}$, Criss Koba Mjumbe ${ }^{2}$, Isabelle Kasongo Omba ${ }^{2}$, \\ Franck Omangelo Shongo ${ }^{3}$, Nora Mwamini Asani' ${ }^{3}$, Beatrice Koba Bora ${ }^{3}$
}

\begin{abstract}
${ }^{1}$ Department of Internal Medicine, Jason Sendwe Reference General Hospital, Lubumbashi, Democratic Republic of Congo ${ }^{2}$ Department of Public Health, Faculty of Medicine, University of Lubumbashi, Lubumbashi, Democratic Republic of Congo ${ }^{3}$ Department of Neuropsychiatry, Faculty of Medicine, University of Lubumbashi, Lubumbashi, Democratic Republic of Congo Email: *cryss_koba25@yahoo.fr
\end{abstract}

How to cite this paper: Lele Mutombo, F., Koba Mjumbe, C., Kasongo Omba, I., Omangelo Shongo, F., Mwamini Asani, N. and Koba Bora, B. (2019) State of the Places of Senile Dementia in the Old Hospice of the City of Lubumbashi. Advances in Alzheimer's Disease, 8, 39-46.

https://doi.org/10.4236/aad.2019.84004

Received: November 20, 2019

Accepted: December 27, 2019

Published: December 30, 2019

Copyright (c) 2019 by author(s) and Scientific Research Publishing Inc. This work is licensed under the Creative Commons Attribution International License (CC BY 4.0).

http://creativecommons.org/licenses/by/4.0/

\begin{abstract}
The objective of this study was to describe the state of the scene of senile dementia in an intra-institutional environment in the city of Lubumbashi. We conducted a descriptive cross-sectional study, over a period of three months, from February 20 to May 20, 2016. The study population is made up of the residents of the 9 retirement institutions for senior citizens (old people's home) which counts the city of Lubumbashi. Participation was voluntary with informed consent duly signed by the patient. The probable cases of dementia were detected through the CSI-D and the 5-word test. A predominance of Alzheimer's was noted (76.92\%) and most of them were widowed (69.23\%). The mean age of the dementia population was $76.46 \pm 9.87$ years, while (69.23\%) of the patients were out of school. In (23.08\%) cases demented patients were male, with a sex ratio of 0.3 . Nearly $(46.15 \%)$ of the demented were drinking. It appears that (69.23\%) of the dementias were hypertensive. There are associations between different risk factors and the presence of dementias. Alcohol with an OR (Odd Ratio) $=0.08$ (95\% CI [0.01 - 0.72], p < 0.05). In our environment, our results indicate a different situation with a much higher prevalence.
\end{abstract}

\section{Keywords}

State of Play, Senile Dementia, Old Hospice, City of Lubumbashi/RD Congo

\section{Introduction}

WHO (1994) defines dementia as a progressive alteration of memory and ideation, sufficiently marked to handicap the activities of everyday life. This alteration must have appeared for at least six months and be associated with a disorder 
of at least one of the following functions: language, calculation, judgment, abstract thinking, praxies, gnosies, or modifications of the personality [1]. APA, for its part, characterizes dementia as an insidious and progressive syndrome characterized by multiple deficits, at the head of which necessarily include memory disorders. Memory problems must be accompanied by at least one other type of deficit (language, praxis, gnosis or executive function). These cognitive deficits must be a decline compared to previous abilities and they must compromise the professional or social activities of the person. Finally, they must not be linked to delirium or psychiatric illness [2] [3] [4]. Dementias can be classified according to two degenerative types (Alzheimer's disease, frontotemporal dementia, Lewy body dementia) or nondegenerative (vascular, traumatic, infectious, toxic and metabolic). The dementia of old people is for the most part represented by Alzheimer's disease and vascular dementia. AD is the most common neurodegenerative dementia, it is predominantly cortical. It is the leading cause of dementia in the elderly. It can be defined as a progressive, global and homogenous alteration of cognitive functions, vegetative functions and motor functions, in a picture of loss of autonomy and social "disintegration" of the subject of slow but inexorable evolution. The diagnostic criteria established for $\mathrm{AD}$ are those of NINCDS-ADRDA. These criteria have recently been revised by Dubois et al. [5]. Vascular dementia is the second most common type of dementia in the elderly. The diagnosis can be based on the patient's history, on the modified Hachinski score and also on the NINCDS-AIREN criteria. The objective of this study was to describe an inventory of senile dementia in an institutional setting in the city of Lubumbashi.

\section{Methodology}

\subsection{Patients}

The study population is made up of the residents of the 9 pension institutions for senior citizens (old people's home) that the city of Lubumbashi has. Participation was voluntary with informed consent duly signed by the patient.

\subsection{Methods}

We conducted a descriptive cross-sectional study over a period of three months, from February 20 to May 20, 2016. Our study parameters were socio-demographic and medical history (including a history of cardiovascular disease and head trauma), psychiatric and family, as well as current medical treatment if available; the probable cases of dementia were detected through the CSI-D [4] and the 5 -word test [5]. During screening, a medical examination was performed to collect certain variables such as: Blood pressure with measurement of systolic and diastolic pressures $(\mathrm{mmHg})$ to detect possible hypertension (hypertension); the weight $(\mathrm{kg})$ and the height $(\mathrm{cm})$, which will make it possible to calculate the Body Mass Index (weight/height ${ }^{2}$ ), classified in the following way: BMI $<18.5$ $\mathrm{kg} / \mathrm{m}^{2}$ (under-weight), $18.5 \leq \mathrm{BMI} \leq 24.9 \mathrm{~kg} / \mathrm{m}^{2}$ (normal weight), $25.0 \leq \mathrm{BMI} \leq$ 
$29.9 \mathrm{~kg} / \mathrm{m}^{2}$ (overweight), BMI $\geq 30 \mathrm{~kg} / \mathrm{m}^{2}$ (obesity); Alcohol consumption, in 3 categories: never, sometimes, regularly; Tobacco consumption. Subjects who scored poorly on the CSI-D $(<25.5)$ or poor performance on the 5-word test $(<10 / 10)$ and met the diagnostic criteria of the DSM-IV were recognized as insane. The Hachinski score allowed us to discern the vascular, degenerative or mixed origin of cognitive deterioration. This study only concerned old people living in different hospices in the city of Lubumbashi. Did not include in this study all the old people who do not resident in the different hospices of the city. Data entry, data management and statistical analysis were entirely performed using the Epi info software (version 7.2). The means, medians and standard deviations were calculated to describe the quantitative variables (age, height, weight, etc.). Frequencies (in number and percentage) were calculated for all qualitative variables of interest. The unadjusted Chi-2 test was used for comparisons when the observed population was $>5$, Yates-adjusted Chi- 2 when the numbers were observed between 3 and 5, and Fisher's exact test when the numbers observed were too weak. The degree of significance for all statistical analyzes was set at 0.05 . Bivariate analyzes were performed to measure the association between risk factor and occurrence of dementia and these factors were included in a multi-variant logistic regression step-by-step model to allow us to minimize confounding factors (factors medical, socio-demographic and psychosocial).

\section{Results}

We had a general population of 83 inmates, $62(74.70 \%)$ of whom signed their agreements for participation in the study. After a medical examination, the CSID test, the 5-word test, the application of the diagnostic criteria DSM IV and NINCDS-ADRDA, we selected 13 demented subjects, i.e. (20.97\%) of the surveyed population.

After applying the NINCDS-ADRDA diagnostic criteria and the Hachinski score, we noticed a probable predominance of Alzheimer's with 10 out of the 13 cases, a relative frequency of $(76,9 \%)$ and the most of them were widowed (69.2\%) (Table 1).

\subsection{Age and Schooling of Patients}

The prevalence of dementia decreases with age, 7 demented subjects, i.e. (53.85\%), was between 64 and 72 years old. The mean age of the demented population is $76.5 \pm 9.8$ years and of the 13 demented subjects, $9(69.2 \%)$ were out of school.

\subsection{Anamnestic Data of Patients}

In $(23.08 \%)$ cases demented patients were male, with a sex ratio of 0.3 . Nearly (46.2\%) of the delinquents used alcohol (9.7\%) of the general population. Uncorrected Chi-2 is 4.33 with a p-value of 0.038 . The association between 
Table 1. Origin of the dementia according to the diagnostic criterion of Nincds-Adrda and the Hachinski score and marital status.

\begin{tabular}{ccc}
\hline Settings & Number (nber) & Frequency (\%) \\
\hline TYPE OF DEMENTIA & & \\
ALZHEIMER (PROBABLE) & 10 & 76.92 \\
MIXED & 1 & 7.69 \\
VASCULAR & 2 & 15.38 \\
MARITAL STATUS & 1 & \\
Single & 9 & 7.69 \\
Widowed/widowed & 3 & 69.23 \\
Divorced/separated & & 23.08 \\
Total & 13 & $100.00 \%$ \\
\hline
\end{tabular}

alcoholism and dementia is statistically significant.

It appears that $(69.2 \%)$ of the dementias were hypertensive, that is to say $14.51 \%$ of the general population. The Chi-2 corrected is 3.62 with a p-value of 0.05 . The association between hypertension and dementia is statistically significant.

There are associations between different risk factors and the presence of dementias (Table 2). The variables significantly and independently associated with the presence of dementia in these populations were: Alcohol, with an $\mathrm{OR}=0.08$ (95\% CI $[0.01-0.72], \mathrm{p}<0.05)$, hypertension with an OR $=8.43$ (95\% CI [1.45 87.47], $\mathrm{p}<0.05$ ), The move to the hospice, with an OR $=1.87$ (95\% CI [1.12 3.12 ], $\mathrm{p}<0.05)$ and the change in financial status, with an $\mathrm{OR}=2.57(95 \% \mathrm{CI}$ [1.30 - 5.09], $\mathrm{p}<0.05)$.

\section{Discussion}

\subsection{Intra-Institutional Prevalence of Dementia}

The frequency of institutional dementia (in old people's homes) was 13 out of a total of 62 . This is a relative frequency of (20.97\%). Molero, on the Caribbean coast of Venezuela found that the prevalence of dementia of all types was 10.3\% in the over-65s [6]. In India, the prevalence is even lower in the city of Chennai, lower at 1\% [7] and in Egypt, the gross prevalence of dementia of all types was $6.0 \%$ [8]. In our study, the figures are higher than the other studies. This difference is probably due to the methodology used.

\subsection{Typing of Dementia}

Alzheimer was predominant in our study with 10 out of 13 cases, a relative frequency of (76.92\%); followed by vascular dementia with (15.38\%) and mixed dementia with (7.69\%). In Latin America, mainly Venezuela, MA representing the most common type of dementia is 50\% [6], while another study in Sri Lanka reported that AM was the most common type of dementia (71.4\%), followed by vascular dementia (14.3\%). On the other hand, in French-speaking Africa, Guerchet finds that Among the 130 subjects diagnosed as demented, 100 had a 
Table 2. Factors associated with dementia in hospices of old Lubumbashi.

\begin{tabular}{|c|c|c|c|}
\hline Settings & OR & IC $95 \%$ & p-Value \\
\hline AGE & 1.04 & $0.97-1.11$ & 0.29 \\
\hline $\operatorname{SEX}(M / F)$ & 0.29 & $0.05-3.97$ & 0.19 \\
\hline ALCOHOL (YES/NO) & 0.08 & $0.01-0.72$ & 0.03 \\
\hline TOBACCO (YES/NO) & 0.84 & $0.07-13.45$ & 0.89 \\
\hline HTA (YES/NO) & 8.43 & $1.45-87.47$ & 0.02 \\
\hline SCHOOLING (YES/NO) & 0.71 & $0.15-4.33$ & 0.68 \\
\hline \multicolumn{4}{|l|}{ BUSINESS EXERCISE: } \\
\hline OTHER & 0.10 & $0.00-2.44$ & 0.16 \\
\hline INACTIVE & 0.78 & $0.11-5.64$ & 0.81 \\
\hline EMPLOYEE & 0.69 & $0.06-7.47$ & 0.76 \\
\hline \multicolumn{4}{|l|}{ MARITAL STATUS: } \\
\hline DIVORCED/SEPARATED & 0.98 & $0.03-29.03$ & 0.9922 \\
\hline MARIE/COUPLE & 0.00 & $0.00->1.0 \mathrm{E} 12$ & 0.9713 \\
\hline WIDOW (WIDOW)/CELIBATAIRE & 1.03 & $0.04-23.96$ & 0.9847 \\
\hline \multicolumn{4}{|l|}{ EVENT EVROVING: } \\
\hline LOSS OF A PARENT (YES/NO) & 1.31 & $0.76-2.24$ & 0.33 \\
\hline HAVE GRANDI WITH ONE PARENT (YES/NO) & 0.91 & $0.55-1.51$ & 0.711 \\
\hline HAVE GRANDI WITH OTHERS (YES/NO) & 0.89 & $0.52-1.53$ & 0.676 \\
\hline LOSS OF A SPOON (YES/NO) & 0.90 & $0.56-1.45$ & 0.666 \\
\hline $\begin{array}{l}\text { SEVERE PHYSICAL DISEASE OF A SPOUSE } \\
\text { (YES/NO) }\end{array}$ & 0.73 & $0.44-1.22$ & 0.231 \\
\hline SERIOUS DISEASE OF A CHILD (YES/NO) & 0.94 & $0.56-1.59$ & 0.816 \\
\hline REMOVAL TO THE HOSPICE (YES/NO) & 1.87 & $1.12-3.12$ & 0.017 \\
\hline CHANGE OF FINANCIAL STATUS (YES/NO) & 2.57 & $1.30-5.09$ & 0.006 \\
\hline
\end{tabular}

possible or probable $\mathrm{AD}, 28$ a vascular dementia [9].

\subsection{Age, Sex and Schooling}

The prevalence of dementia decreases with age, 7 demented subjects (53.85\%), is between 64 and 72 years old. The mean age of the demented population is 76.46 \pm 9.87 years, the median age is 76 years, and the extreme ages are 65 and 96 years. This corroborates the observations of etGuerchet who found that $59 \%$ of the total population of his 4 studies was 65 to 74 years old, the overall average age was $73.9 \pm 7.4$ years [9]. Decrease cases of advanced dementia could be explained by Anne-Claire Samba's study which shows that demented subjects have a higher risk of death. This risk is 2.5 times higher compared to normal subjects $(\mathrm{HR}=2.53,95 \% \mathrm{CI}: 1.42-4.49, \mathrm{p}=0.001)$ and increased with age and severity of the disease [10]. In contrast, Farrag notes that the prevalence of dementia and $\mathrm{AD}$ increased with age, however, the doubling of dementia prevalence by 5-year-olds was only observed after 75 years [8]. 
Of the 13 subject with dementia, 10 of them were female, which is a relative frequency of $16 \%$. The sex ratio $\mathrm{M} / \mathrm{F}$ being 0.3 . According to the literature, the incidence of dementia tends to be higher in women than in men. Hérrera et al., in 2002 in Brazil, found an M/F ratio of 0.69 [11] and Scazufca et al. in 2008 still in Brazil finds a ratio M/F of 0.65 [12]. Hendrie et al. in Nigeria in 1995 found an $\mathrm{M} / \mathrm{F}$ ratio of 0.53 [13] and 0.70 according to Guerchet [9]. In contrast, Farrag et al., in 1998, in Egypt found a sex ratio M/F of 1.05 [8]. In our study population, illiteracy is predominant in 9 subjects against 13 who studied. That is a frequency of $69.23 \%$, of individuals who have never been to school. Guerchet found a lower rate than us $57 \%$ of those older subjects had never been to school [9] and Farrag finds that in Egypt, prevalence was affected by the subjects' level of education [8]. In South America, illiteracy or a low level of education is correlated with the cases of dementia encountered according to Llibre Rodriguez et al., 2008 [7].

\subsection{Multivariate Analyzes}

In our cohort, alcohol appears to be a protective factor. Subjects who regularly consumed alcohol were less likely $(\mathrm{OR}=0.08)$ to develop dementia. With a OR $=0.08(95 \%$ CI $[0.01-0.72], \mathrm{p}<0.05)$, HTA, Hospice relocation and change of financial status: challenging events and referral generator depressed mood for more than one subject, have been risk factors associated with dementia. This corroborates the observations of the several studies establishing a correlation between certain risk factors and dementia. In Latin America, low income or poverty has been reported in several studies [12] [14]. The history of hypertension was significantly associated with vascular dementia in a rural community in Kerala, India, whereas age, sex and family history was associated with $\mathrm{AD}$ [7] [15], In Senegal, the prevalence of dementia in the population was $6.6 \%$, it increased with age and was not influenced by sex or marital status. The risk factors identified were age, poor weekly contact with loved ones, stroke, epilepsy, and family history of dementia. Among the Yorubas, the risk factors for AD were age and female sex, while reporting a medical history of hypertension seemed protective. Age was also an associated risk factor for AD in African Americans and life in rural areas before age 19, but regular alcohol consumption appeared to be protective [13] [16]. Finally, Guerchet in a study conducted in Central Africa, Benin and the Republic of Congo, shows that the variables significantly and independently associated with dementia were age, sex, a body mass index of less than $18.5 \mathrm{~kg} / \mathrm{m}^{2}$, the existence of anxiety disorders and depressive symptoms at the time of the study [8].

\section{Conclusions}

In our environment, our results indicate a different situation with a much higher prevalence. Also, some factors studied, such as: history of alcoholism, hypertension, moving to a home and change of financial status are associated with dementia, reflecting the multifactorial origin of these neurodegenerative disorders. 
The identification of modifiable risk factors such as social inclusion here opens the door to opportunities for preventive strategies that focus on the creation of recreational facilities for older people.

It is therefore clear that senile dementia is a public health problem, and further studies in the general population could broaden knowledge about the epidemiology of dementias in our environment.

\section{Conflicts of Interest}

The authors declare no conflicts of interest regarding the publication of this paper.

\section{References}

[1] World Health Organization (1994) International Statistical Classification of Diseases and Related Health Problems. 10th Revision, WHO, Geneva, Switzerland.

[2] American Psychiatric Association (2000) Diagnostic and Statistical Manual of Mental Disorders. Fourth Edition, Text Revision, Washington.

[3] Dubois, B., Feldman, H.H., Jacova, C., Dekosky, S.T., Barberger-Gateau, P., Cummings, J., Delacourte, A., Galasko, D., Gauthier, S., Jicha, G., Meguro, K., O’Brien, J., Pasquier, F., Robert, P., Rossor, M., Salloway, S., Stern, Y., Visser, P.J. and Scheltens, P. (2007) Research Criteria for the Diagnosis of Alzheimer's Disease: Revising the NINCDS-ADRDA Criteria. The Lancet Neurology, 6, 734-746. https://doi.org/10.1016/S1474-4422(07)70178-3

[4] Hall, K.S., Hugh, C., Hendrie, H.C., Brittain, H.M., Norton, J.A., Rodgers, D.D., Prince, C.S., Pillay, N., Blue, A.W., Kaufert, J.N., Nath, A., Shelton, P., Postl, D.B. and Osuntokun, B.O. (1993) The Development of a Screening Interview in Two Distinct Languages. International Journal of Methods in Psychiatric Research, 3, $1-28$.

[5] Dubois, B., Touchon, J., Portet, F., Ousset, P.J., Vellas, B. and Michel, B. (2002) "The 5 Words": A Simple and Sensitive Test for the Diagnosis of Alzheimer's Disease. La Presse medicale, 31, 1696-1699.

[6] Molero, A.E., Pino-Ramirez, G. and Maestre, G.E. (2007) High Prevalence of Dementia in a Caribbean Population. Neuroepidemiology, 29, 107-112. https://doi.org/10.1159/000109824

[7] Llibre Rodriguez, J.J., Ferri, C.P., Acosta, D., Guerra, M., Huang, Y., Jacob, K.S., Krishnamoorthy, E.S., Salas, A., Sosa, A.L., Acosta, I., Dewey, M.E., Gaona, C., Jotheeswaran, A.T., Li, S., Rodriguez, D., Rodriguez, G., Kumar, P.S., Valhuerdi, A. and Prince, M. (2008) Prevalence of Dementia in Latin America, India, and China: A Population-Based Cross-Sectional Survey. The Lancet, 372, 464-474. https://doi.org/10.1016/S0140-6736(08)61002-8

[8] Farrag, A., Farwiz, H.M., Khedr, E.H., Mahfouz, R.M. and Omran, S.M. (1998) Prevalence of Alzheimer's Disease and Other Dementia Disorders: Assiut-Upper Egypt Study. Dementia and Geriatric Cognitive Disorders, 9, 323-328. https://doi.org/10.1159/000017084

[9] Guerchet, M., Mbelesso, P., Ndamba-Bandzouzi, B., Pilleron, S., Now, I., Lacroix, P., et al. (2014) Epidemiology of Dementia in Central Africa (EPIDEMCA): Protocol for a Multicentre Population-Based Study in Rural and Urban Areas of the Central African Republic and the Republic of Congo. SpringerPlus, 3, 1044. 
https://doi.org/10.1186/2193-1801-3-338

[10] Samba, H., Guerchet, M., Ndamba-Bandzouzi, B., Mbelesso, P., Lacroix, P., Dartigues, J.F. and Preux, P.M. (2016) Link between Dementia and Mortality in Congolese Subjects: Epidemca-FU Program (Two-Year Follow-Up of the EPIDEMCA Cohort). Neurological Review, 172, A11. https://doi.org/10.1016/j.neurol.2016.01.017

[11] Herrera Jr., E., Caramelli, P., Silveira, A.S. and Nitrini, R. (2002) Epidemiologic Survey of Dementia in a Community-Dwelling Brazilian Population. Alzheimer Disease and Associated Disorders, 16, 103-108. https://doi.org/10.1097/00002093-200204000-00007

[12] Scazufca, M., Menezes, P.R., Araya, R., Di Rienzo, V.D., Almeida, O.P., Gunnell, D. and Lawlor, D.A. (2008) Risk Factors in the Brazilian Population: Results from the Sao Paulo Aging and Health Study (SPAH). International Journal of Epidemiology, 37, 879-890. https://doi.org/10.1093/ije/dyn125

[13] Hendrie, H.C., Osuntokun, B.O., Hall, K.S. and Ogunniyi, A.O. (1995) Prevalence of Alzheimer's Disease and Dementia in Two Communities: Nigerian Africans and African Americans. American Journal of Psychiatry, 152, 1485-1492. https://doi.org/10.1176/ajp.152.10.1485

[14] Kalaria, R.N., Maestre, G.E., Arizaga, R., Friedland, R.P., Galasko, D., Hall, K., Luchsinger, J.A., Ogunniyi, A., Perry, E.K., Potocnik, F., Prince, M., Stewart, R., Wimo, A., Zhang, Z.X. and Antuono, P. (2008) Alzheimer's Disease and Vascular Disease in Developing Countries: Prevalence, Management, and Risk Factors. The Lancet Neurology, 7, 812-826. https://doi.org/10.1016/S1474-4422(08)70169-8

[15] Chandra, V., Ganguli, M., Pandav, R., Johnston, J., Belle, S. and DeKosky, S.T. (1998) Prevalence of Alzheimer's Disease and Other Disease in Rural India: The Indo-US Study. Neurology, 51, 1000-1008. https://doi.org/10.1212/WNL.51.4.1000

[16] Osuntokun, B.O., Sahota, A., Ogunniyi, A.O., Gureje, O., Baiyewu, O., Adeyinka, A., Oluwole, S.O., Komolafe, O., Hall, K.S., Unverzagt, F.W., Hui, S.L., Yang, M. and Hendrie, H.C. (1995) Lack of an Association between Apolipoprotein and Epsilon 4 and Alzheimer's Disease in Elderly Nigerians. Annals of Neurology, 38, 463-465. https://doi.org/10.1002/ana.410380319 